\title{
Nutrition Education Practices of Primary School Teachers in a Resource- Constrained Community in Gauteng, South Africa
}

\author{
Mojisola D. Kupolati ${ }^{\mathrm{a}}$, Gerda J. Gericke ${ }^{\mathrm{a}}$, Una E. MacIntyre ${ }^{\mathrm{a}}$, Ronel Ferreira ${ }^{\mathrm{b}}$, \\ William Fraser ${ }^{\mathrm{c}}$, and Peet Du Toit ${ }^{\mathrm{d}}$ \\ ${ }^{a}$ Faculty of Health Sciences, Department of Human Nutrition, University of Pretoria, Pretoria, South Africa; \\ ${ }^{b}$ Faculty of Education, Department of Educational Psychology, University of Pretoria, Pretoria, South Africa; \\ ${ }^{c}$ Faculty of Education, Department of Science, Mathematics and Technology Education, University of Pretoria, \\ Pretoria, South Africa; \\ ${ }^{\mathrm{d}}$ Faculty of Health Sciences, Department of Human Physiology, University of Pretoria, Pretoria, South Africa.
}

\begin{abstract}
We investigated the nutrition education (NE) practices of teachers of grade 4-7 learners in 11 primary schools (85\% of total number) of the Bronkhorstspruit district (Gauteng Province) to identify opportunities for improving NE in these schools. A descriptive cross-sectional survey was carried out among a convenient sample of the teachers $(\mathrm{N}=73)$ using a structured nutrition education practice questionnaire. Descriptive data analysis was done. Results showed that the majority of the teachers taught nutrition in about $10 \%$ to $20 \%$ of their teaching time. Thirty percent had no training to teach nutrition, and most teachers $(86 \%)$ would like to receive training in nutrition. Teachers mostly taught nutrition as part of the curriculum $(67 \%)$ and very few $(18 \%)$ integrated nutrition into other subjects. Needing improvement were adequate classroom time for nutrition education delivery, continuing training in nutrition for teachers, and provision of up-to-date instructional materials for teaching nutrition.
\end{abstract}

Keywords: Learners' health; nutrition education; nutrition education practices; nutrition instructional materials; nutrition teaching time; nutrition training.

Nutrition is an important pillar of a thriving nation. Therefore, nutrition education (NE) in schools can contribute to the health of learners and eventually to sustainable manpower development in developing nations (FAO 2005). The nutritional well-being of schoolchildren contributes to their physical and intellectual development and is necessary to promote their school performance. Good nutrition prevents the occurrence of malnutrition, such as undernutrition, micronutrient deficiencies, obesity, and diet-related diseases. In addition, school-based NE can help to raise nutritionally literate and healthy adolescent girls whose eventual healthy pregnancy outcomes will secure the health of future generations (CSFSA 2003; Procter and Campbell 2014). The school setting provides a feasible platform to promote healthy eating behavior and physical activity habits for children. However, the approach of teachers to teaching nutrition can determine to a great extent the effect of school NE on the nutritional wellbeing of learners (Kupolati, Gericke, and MacIntyre 2015). Oldewage-Theron and Egal (2012) reported that the nutrition knowledge of teachers was not optimal, and Rafiroiu and Evans (2005) reported it to be fair but with positive attitudes. According to Rossiter et al. (2007), nutrition knowledge, attitudes, and behaviors of 
prospective teachers can be barriers to promoting healthy food habits among learners. Some of the roles expected of teachers in connection with NE in schools include teaching nutrition to impart nutrition knowledge and improve eating behaviors, teaching nutrition with commitment and an interest in diet and a healthy lifestyle, modeling desirable nutrition behaviors for learners, and using nutrition issues to explain topics in other subjects, thereby increasing nutrition awareness through multiple sources (Culinary Institute of America 2012; FAO 2005; UNICEF 2009).

The teaching of nutrition in schools to enhance healthy eating behavior can be challenging. The barriers to providing effective NE in schools include time constraints for teaching, teachers' lack of nutrition science training, limited curriculum materials, and limited support from the school administration (CSFSA 2003; Kupolati, Gericke, and MacIntyre 2015). Several recommenda- tions have been suggested to promote effective NE in schools. The Academy of Nutrition and Dietetics (AND) recommended that NE be integrated into a comprehensive health package through other school subjects. The AND also recommended the integration of the school cafeteria, physical education classes, physical activity, parents, and community involvement into NE in schools (CSFSA 2003). The Nutrition Friendly School Initiative (NFSI) of the World Health Organization (WHO) has the following key components: creating awareness and building capacity in the school community, developing a nutrition- and health-promoting school curriculum, providing a supportive school environment, and providing school nutrition and health services (WHO 2006). The FAO (2005) recommended a threefold curriculum approach to NE in schools whereby nutrition learning takes place in the classroom, in the school environment, and in the family and community.

In South Africa, the activities and initiatives of NE reside under the umbrella of the Integrated Nutrition Programme (INP) (DOH 2008). The INP proposed nutrition promotion and education as one of its immediate goals with the vision to reduce malnutrition. It also recommended the use of the South African Food-Based Dietary Guidelines (SAFBDG) in the implementation of NE programs (DOH 2008). The National School Nutrition Programme (NSNP) of the Department of Basic Education (DoBE) complements the efforts of the INP (DoBE 2015). In South African primary schools, nutrition is usually taught as a topic in subjects such as Health Science or Health Education, Life Skills/Life Orientation (LS/LO), and Natural Science and Technology (NST) (DoBE 2011a, 2011b; KPMG 2008). Nutrition is also taught by integrating nutrition lessons into other subjects such as physical education, history, languages, arts, and social studies (CSFSA 2003; Celebuski and Farris 2000; McNulty 2013). However, limited data exist concerning the teaching of nutrition in primary schools in South Africa. This study aimed to increase the knowledge base of the practices of teachers in the provision of NE to learners in grades 4-7 in the Bronkhorstspruit district. 


\section{Methods}

\section{Setting}

The study was conducted between July and September 2013 in 11 primary schools in the Bronkhorstspruit district, a resource-constrained community east of Pretoria in Gauteng province. The district was selected on the recommendation of the Gauteng DoBE. The educational district has 13 government primary schools.

\section{Population and sample}

All 13 schools were invited to participate in the study, but two schools declined to participate. Inclusion criteria were teachers who taught LS/LO and NST in grades 4-7 at the time of the survey. Teachers who taught nutrition topics were more likely to provide useful information about the teaching of nutrition than those who did not. A total of 100 eligible teachers were identified by the principals of the 11 schools. The eligible teachers were sent a letter introducing the study and inviting them to participate. Only 73 teachers who signed the informed consent letters were involved in the survey.

\section{Questionnaire}

The questionnaire was developed with information from the survey instrument of the National Centre for Education Statistics: Nutrition Education in Public Elementary Schools (Celebuski and Farris 2000). The validated instrument was used to address high-priority nutrition education needs among elementary schools in the United States. This instrument was considered suitable for use among the primary schools in Bronkhorstspruit because the ages for learners in elementary schools in America and primary schools in South Africa (ages 6-7 to 12-13 for first grade through seventh grade) are similar (Statistics South Africa 2010; U.S. Department of Education-NCES 2015). The instrument was adjusted by the principal investigator to be appropriate for the situation of primary schools in Bronkhorstspruit. First, the education level for primary school teachers was adjusted to reflect South African teacher qualifications. Second, the educational structure and subject terms were adjusted to portray the situation and structures in South African primary schools. Some of the adjustments included the subject/study area nomenclature, policy issues, and support for nutrition education in schools. The terms "R-Grade 7" and "Grade R" were used instead of "K-Grade 5" and "Kindergarten," respectively. The survey instrument consisted of 18 questions covering areas such as the grades where nutrition was taught, teacher training, methods of teaching, materials in use, and teaching time. Questions included the following: "Rate the quality of instructional materials currently in use for NE"; "Indicate the availability of resources in support of NE in your school"; and "Would you like to receive in-service training on various nutrition topics?" The instrument was subjected to face and content validity by nutrition education experts at the University of Pretoria, after which it was pretested in one school, randomly selected from the participating schools, among a convenient sample of nine teachers who were also part of the larger sample. The instrument was tested for readability, clarity, and ease of completion. The teachers adjudged the instrument to be readable, clear, and easy to understand, except for the question requesting 
the number of hours nutrition was taught. This question was therefore adjusted to solicit the proportion of time that nutrition was taught.

The questionnaire comprised questions which were categorical variables; therefore Cronbach's alpha reliability test was performed to test the internal reliability of each area covered by the questionnaire. A Cronbach's alpha of 0.8 was obtained for areas on the integration of nutrition into other subjects, the availability of resources in support of NE and the extent to which various resources can improve NE. The Cronbach's alpha for questions on the rating of the quality of instructional materials and the extent to which various instructional materials will aid the teaching of nutrition was 0.9 .

\section{Data collection}

The questionnaires were self-administered. The principal investigator delivered the questionnaires to the teachers and allowed them to complete the questionnaires at their convenience and have them ready for collection on an agreed date. Reminders were sent, and visits to the schools were repeated until all the completed questionnaires were collected. The questionnaires were completed individually by the teachers. This allowed for personal responses without external influence or coercion. The method contributed to the validity of the data.

\section{Data analysis}

Duplicate data entry was done using Microsoft Excel. The two data sets were compared, and errors were corrected. Data were analyzed using Stata Statistical Software Release 10, 2007 for the descriptive statistics. The variables of age and years of teaching experience presented skewed distributions as revealed by histograms, but were not significant when subjected to the Shapiro-Wilk test ( $\mathrm{V}=2.5$ and 1.3, respectively, $p>.05$ ) (Ghasemi and Zahediasl 2012). These variables were therefore reported both as means and medians to present central tendency and as standard deviations $(S D)$ and ranges to present the dispersion. A linear regression analysis was done to determine the relationship between independent and dependent variables. The independent variables of interest were gender and highest education qualification (Teaching diploma, University first degree, Master's degree, and others). The dependent variables were research and personal study as methods to prepare to teach nutrition; desire to receive in-service training in nutrition topics; the use of teacher materials (e.g. curriculum), and the use of textbooks.

\section{Ethical approval}

Permission to conduct the study in the schools was granted by the Gauteng DoBE with the reference number D2014/199. Ethical approval for the study was granted by the Ethics Committee of the Faculty of Natural and Agricultural Sciences of the University of Pretoria (EC130424-037). 


\section{Results}

Participants were mostly black (93\%) and female $(65 \%)$ with a mean age of 47 years $(S D=$ 6.1 ) and a median age of 46 years (range 27-55). The mean years of teaching experience was $19(S D=8.2)$ with a median of 20 years (range $1-35)$. The teachers $(92 \%)$ were in full-time employment and had a teaching diploma (46\%) as the highest educational qualification.

Most of the teachers (80\%) had taught grades 5-7 in the past, and about half taught LS/LO and other subjects at the time of survey (table 1). Only $9 \%$ and $6 \%$ of the teachers taught LS/LO and NST, respectively, as their only subject.

Table 1. Grades Where Nutrition Was Taught and the Subjects Teachers Taught at Time of the Survey $(N=66)$

\begin{tabular}{|l|l|}
\hline Characteristics & $\mathbf{n}(\mathbf{\%})$ \\
\hline Grade or grades taught $(\mathbf{n = 6 6 )}$ & $7(10.6)$ \\
Grades R through grade 6 & $6(9.1)$ \\
Grades 2-4 & $53(80.3)$ \\
Grades 5-7 & \\
Subjects teachers taught (n=64) & \\
Life skills/Life Orientation only & $6(9.4)$ \\
Natural Science and Technology only & $4(6.3)$ \\
Life skills/Life Orientation and other subjects \\
Natural Science and Technology and other subjects & $32(50.0)$ \\
& $22(34.4)$ \\
\hline
\end{tabular}

Note. Percent was based on total number of responses (n).

Table 2. Proportion of Classes in Which Nutrition Was Taught, Training Received for Teaching Nutrition, and Methods Used $(N=66)$

\begin{tabular}{|l|l|}
\hline Characteristics & n (\%) \\
\hline Proportion of classes where nutrition was taught $(\mathbf{n = 5 8})$ & $35(60.3)$ \\
$10-20 \%$ & $11(19.0)$ \\
$21-40 \%$ & $12(20.7)$ \\
$41-60 \%$ & \\
Training for teaching nutrition & $22(45.8)$ \\
In-service training (n=48) & $15(31.3)$ \\
Undergraduate or graduate training (n=48) & $27(57.5)$ \\
Research and personal study (n=47) & $17(30.4)$ \\
No training (n=56) & $57(86.4)$ \\
Desire to receive in-service training on various nutrition topics (n=66) & \\
Formal methods used to teach nutrition & $11(18.0)$ \\
By integrating nutrition lessons into various subjects (n=61) & $31(66.9)$ \\
Nutrition as part of the curriculum (n=47) & \\
\hline
\end{tabular}

Note. Percentages do not equal 100 because teachers might have selected more than one option. Percentage was based on total number of responses $(n)$.

Almost half of the teachers (46\%; table 2) had received in-service nutrition training, while $58 \%$ prepared to teach nutrition though research and personal study. Less than a third of the 
teachers $(30 \%)$ had no training in teaching nutrition, while most of the teachers $(86 \%)$ indicated they would like to receive in-service training.

The majority of teachers $(60 \%)$ had taught nutrition in about $10 \%$ to $20 \%$ of their classes in the previous academic year (table 2). Nutrition was taught where it appeared in the curriculum by $66 \%$ of the teachers. Only $18 \%$ of the teachers reported that they taught nutrition by integrating it into lessons other than where nutrition appeared in the curriculum. The details of integrating nutrition into other subjects (table 3) showed the teachers' insights about this challenge. The teachers interpreted their teaching of nutrition in LS/LO and NST as integrating it into other subjects. Nutrition was integrated by $68 \%$ and $39 \%$ of the teachers into LS/LO and NST, respectively. Nutrition was not integrated at all into Social Sciences, Mathematics, and English language by 50\%, 45\%, and 36\% of the teachers, respectively.

In respect to teachers' responses on the use, quality, and suppliers of instructional materials to teach nutrition, $62 \%$ indicated that there was a general lack of nutrition education

Table 3. Integration of Nutrition Topics into Other Subjects $(N=66)$

\begin{tabular}{|l|l|l|l|l|}
\hline \multirow{2}{*}{ Characteristics } & \multicolumn{4}{|l|}{ Extent to which nutrition lessons were integrated: n (\%) } \\
\cline { 2 - 5 } & Great extent & $\begin{array}{l}\text { Moderate } \\
\text { extent }\end{array}$ & $\begin{array}{l}\text { Limited } \\
\text { extent }\end{array}$ & Not at all \\
\hline $\begin{array}{l}\text { Life Skills/Life Orientation } \\
(\mathrm{n}=59)\end{array}$ & $40(67.8)$ & $7(11.9)$ & $5(8.5)$ & $7(11.9)$ \\
\hline Social Sciences (n=52) & $6(11.5)$ & $8(15.3)$ & $12(23.1)$ & $26(50.0)$ \\
\hline Mathematics (n=56) & $7(12.5)$ & $9(16.1)$ & $15(26.8)$ & $25(44.6)$ \\
\hline English Language $(\mathrm{n}=56)$ & $10(17.9)$ & $15(26.8)$ & $11(19.64)$ & $20(35.7)$ \\
\hline $\begin{array}{l}\text { Natural Science and } \\
\text { Technology (n=58) }\end{array}$ & $23(39.7)$ & $12(20.7)$ & $7(12.1)$ & $16(27.6)$ \\
\hline
\end{tabular}

Note. Percentage was based on total number of responses $(n)$.

Table 4. Teachers' Rating of the Quality of Instructional Materials $(N=66)$

\begin{tabular}{|c|c|c|c|c|}
\hline \multirow[t]{2}{*}{ Quality index } & \multicolumn{4}{|c|}{ Response: n (\%) } \\
\hline & Great extent & $\begin{array}{l}\text { Moderate } \\
\text { extent }\end{array}$ & $\begin{array}{l}\text { Limited } \\
\text { extent }\end{array}$ & Not at all \\
\hline Materials are up to date $(n=64)$ & $11(17.2)$ & $30(46.9)$ & $20(31.3)$ & $3(4.6)$ \\
\hline $\begin{array}{l}\text { Materials are age appropriate } \\
(\mathrm{n}=64)\end{array}$ & $15(23.4)$ & $28(43.7)$ & $16(25.0)$ & $5(7.8)$ \\
\hline $\begin{array}{l}\text { Learners find materials } \\
\text { appealing }(n=63)\end{array}$ & $17(27.0)$ & $17(27.0)$ & $24(38.1)$ & $5(7.9)$ \\
\hline $\begin{array}{l}\text { Enough materials for all } \\
\text { learners }(n=64)\end{array}$ & $12(18.8)$ & $16(25.0)$ & $22(34.9)$ & $14(21.9)$ \\
\hline
\end{tabular}

Note. Percentage was based on total number of responses $(n)$.

instructional materials (teaching and learning aids). The majority of teachers (95\%) would like to receive nutrition education materials to aid their teaching of nutrition. The supplier of instructional materials, as indicated by the majority of teachers (95\%), was the DoBE.

Responses regarding availability of resources in support of NE revealed that $34 \%$ of the teachers were of the view that high-quality in-service training was not available at all, and $49 \%$ indicated that the NSNP was a supportive resource to a great extent. Reference materials 
at schools were reported to be available to a limited extent by $44 \%$ of the teachers. Teachers' responses showed that support for use of instructional time, written guidelines on nutrition, and coordinated school nutrition policy were available to a moderate extent.

Teachers were of the view that all the resources had potential to improve NE to a great extent (e.g., high-quality in-service training, school-provided meals, reference materials at school, and support for use of instructional materials). Teachers rated the instructional materials they used (table 4) as up to date (64\%) and age appropriate (67\%). About one-third of the teachers showed that learners found materials slightly appealing and that there was not always enough material for all learners. Most of the teachers indicated that all the instructional materials would aid their teaching of nutrition to a great extent (table 5). The materials included teacher materials (e.g., curriculum), textbooks, supplementary learner materials (e.g., worksheets), learner assessment materials, computer software, and audio and visual aids (e.g., films, videotapes, posters).

Table 5. Teachers' Response to the Extent to Which Various Instructional Materials Would Aid Their Teaching Nutrition $(N=66)$

\begin{tabular}{|l|l|l|l|l|}
\hline \multirow{2}{*}{ Type of material } & \multicolumn{3}{|l|}{ Extent to which materials will be useful: $\mathrm{n}(\%)$} \\
\cline { 2 - 5 } & Great extent & $\begin{array}{l}\text { Moderate } \\
\text { extent }\end{array}$ & $\begin{array}{l}\text { Limited } \\
\text { extent }\end{array}$ & Not at all \\
\hline $\begin{array}{l}\text { Teacher materials (e.g. curriculum) } \\
\text { (n=65) }\end{array}$ & $41(63.1)$ & $16(24.6)$ & $5(7.7)$ & $3(4.6)$ \\
\hline Textbooks (n=65) & $44(67.7)$ & $16(24.6)$ & $3(4.6)$ & $2(3.1)$ \\
\hline $\begin{array}{l}\text { Supplementary learners materials } \\
\text { (e.g. worksheets) (n=66) }\end{array}$ & $36(54.6)$ & $17(25.8)$ & $10(15.2)$ & $3(4.6)$ \\
\hline $\begin{array}{l}\text { Learners assessment materials } \\
\text { (n=64) }\end{array}$ & $33(51.6)$ & $21(32.8)$ & $7(10.9)$ & $3(4.6)$ \\
\hline Computer software (n=63) & $33(52.4)$ & $10(15.9)$ & $9(14.3)$ & $11(17.5)$ \\
\hline $\begin{array}{l}\text { Audio and visual aids (e.g. films, } \\
\text { video-tapes, posters) (n=64) }\end{array}$ & $32(50.0)$ & $14(21.9)$ & $7(10.9)$ & $11(17.2)$ \\
\hline
\end{tabular}

Note. Percentage was based on total number of responses $(n)$.

A regression analysis (data not shown) of gender and education level with factors that could enhance the teaching of nutrition (research and personal study, in-service training, teachers' materials, and textbooks) showed no significant relationships $(p \geq .05)$.

\section{Discussion}

\section{Main findings}

One of the reasons that the school setting is a suitable platform for NE is that schools have qualified personnel (the teachers) to teach and guide (FAO 2005). However, for teachers to teach effectively and guide, they need to be trained not only in nutrition topics but also on how to deliver nutrition messages by accommodating the learners' circumstances (Kupolati, Gericke, and MacIntyre 2015). In our study, only about half of the teachers had received training to teach nutrition. It has been reported that capacity and skills to teach nutrition are often lacking among teachers who have the responsibility to teach nutrition (FAO 2005; Nguyen et al. 2013). The need for nutrition training for primary school teachers was established in a study that looked into the influence of nutrition and physical activity 
knowledge on the weight status of teachers. Drawing on their findings, the authors recommended that a distance-learning nutrition course be made available for experienced educators (Dalais et al. 2014).

A large proportion of the teachers indicated they would like to receive nutrition training to enable them to teach nutrition effectively. This finding was confirmed in previous studies where teachers admitted inadequacy in teaching nutrition and expressed their need for nutrition training despite many years of teaching experience (Kupolati, Gericke, and MacIntyre 2015; Nguyen et al. 2013). In-service training is a useful resource to sharpen the skills of personnel for better performance. Periodic exposure of teachers to in-service nutrition training can assist teachers in teaching nutrition effectively (Dalais et al. 2014). About one-third of the teachers in our study had not had any opportunities for in-service nutrition training. A South African study that considered the school food environment in relation to healthy eating revealed that most of the teachers showed interest in nutrition, but only $15 \%$ had received nutrition training (Faber et al. 2013). It was further confirmed that providing training for teachers in all the learning areas of LO could facilitate healthy behavioral outcomes (Hill et al. 2015).

In South African primary schools, nutrition topics are taught mostly as part of the curriculum (LS/LO and NST) (DoBE 2011a, 2011b). Teaching nutrition both by integrating it into other subjects and as a separate subject enables nutrition information to reach learners through multiple avenues thereby consolidating the learning and concepts of nutrition (FAO 2005). In our study, most of the teachers $(66 \%)$ taught nutrition as part of the curriculum, and only $18 \%$ of the teachers taught nutrition by integrating it into other subjects. This finding is contrary to the U.S Department of Education survey on the teaching of nutrition, where one-third of the teachers taught nutrition as a separate subject, while the same proportion also taught nutrition by integrating it into other subjects (Celebuski and Farris 2000). In another South African study, $56 \%$ and $21 \%$ of educators taught nutrition as part of LO and NST, respectively (Faber et al. 2013).

The use of instructional materials (teaching and learning aids) such as posters, charts, workbooks, and hands-on materials can greatly enhance the delivery of nutrition lessons to learners. Lack of good-quality teaching and learning materials is an impediment to effective school NE (FAO 2005). About 62\% of the teachers surveyed indicated lack of instructional materials. This finding is consistent with other studies in South Africa, where lack of quality instructional materials hindered the effective teaching of nutrition (Nguyen et al. 2013; Oldewage-Theron and Egal 2012).

The finding that the NSNP was a supportive resource to NE, as indicated by almost half of the teachers, has been confirmed in other South African studies (Faber et al. 2013; Kupolati, Gericke, and MacIntyre 2015). In these studies, teachers reported that the meals from the NSNP served as examples of nutritious meals and formed part of classroom discussions. Teachers rated the various resources such as quality in-service training, NSNP meals, reference materials at school, and support for use of instructional materials as having potentials to improve NE to a great extent. These findings are in line with the 
recommendations that effective school NE should be supported by the school environment, should create awareness and build capacity for NE, and should maintain a sustainable school feeding program (CSFSA 2003; WHO 2006). Teachers indicated that instructional materials were reasonably up to date and age appropriate, but scarcely enough for all the learners. It has been reported elsewhere that teachers had limited resources and curriculum materials to support NE (Lambert and Carr 2006). Most of the teachers in our study indicated that instructional materials such as teachers' manuals, worksheets, computer software, films, videotapes, and posters would aid their teaching of nutrition to a great extent. In their intervention study among public school educators in South Africa, Oldewage-Theron and Egal (2012) found that teachers preferred coloring books, videos, posters and wall charts, and NE card games. These authors recommended a NE manual covering all the nutrition topics outlined in the DoBE curriculum to be used alongside NE tools.

The majority of the teachers indicated they taught nutrition in about $10 \%-20 \%$ of their classes. The teachers had difficulty in stating the number of hours they taught nutrition during the pretesting of the instrument; therefore, the amount of time nutrition was taught was expressed in percentages of teachers' total teaching time. However, the total hours allocated for teaching nutrition in grades 5 and 6 is 3 hours and 22 hours, respectively (DoBE 2011a, 2011b). These allotted numbers of hours do not meet the recommended 50 hours necessary to achieve behavior change in children (Briggs, Fleschhacker, and Mueller 2010). The small proportion of time used to teach nutrition as reported by teachers in our study was confirmed in a study where teachers spent less than one hour per week in teaching nutrition (OldewageTheron and Egal 2012).

The gender of teachers and the highest education qualification did not appear to have any relationship with the factors that could enhance the teaching of nutrition. This finding is not in agreement with findings of Celebuski and Farris, where teachers with no formal training in nutrition mostly used research and personal study to prepare to teach nutrition, and those with college training had more in-service training in nutrition (Celebuski and Farris 2000). This result may be because the situation of the teachers in the United States is different from that of the teachers in this study. The findings from this study emphasize the existing challenges regarding NE in schools as reported in the literature. However, the nonsignificant relationship between the gender of teachers and the education level with factors that can improve NE, such as nutrition training, provides a new understanding that has implications for practice. It is inferred that the training need of the teachers was regardless of their gender and educational qualification.

\section{Limitations}

The survey was conducted in a resource-limited peri-urban area and only in one district; therefore, the generalizability of the findings of the study to the other areas in South Africa may be limited. The need for nutrition training was repeatedly expressed in the study; however, the specific areas where teachers would like to receive training were not explored. Areas such as active learning strategies in NE, integrating nutrition into other subjects, coordinating NE across grades, and/or curriculum nutrition topics could better inform the 
planning of effective training for teachers. The two schools that declined participation, the use of a small convenience sample, and the incomplete responses of all the sections of the questionnaire by the participants might have constituted a source of bias. Valuable information affecting NE practices in school might have been missed as a result of those who refused participation and the unanswered questions. The inclusion of the participants used in the pretesting of the instrument and the adjustment of only one question could constitute a potential source of contamination of the data. However, the fact that the instrument was used to measure practices and not knowledge could minimize the effect. The study is limited in comprehensive assessment involving the learners, school tuck-shop (a small food vending store) operators, parents/ guardians, qualitative interviews with teachers, and content analysis of nutrition topics, which would have provided more holistic information on the practices of $\mathrm{NE}$ in the schools. However, additional information was drawn from the qualitative interviews with a subsample of the teachers (reported elsewhere) (Kupolati, Gericke, and MacIntyre 2015). In addition, the sample size of 66 for the regression analysis was small but was considered adequate according to the formula $N>50+8 m$ (where $m$ is the number of independent variables) (VanVoorhis and Morgan 2007).

\section{Conclusions and recommendations}

The practice of NE by teachers in Bronkhorstspruit cannot be separated from the scope of the authority of the schools (i.e., the DoBE). Inadequate time for teaching nutrition, lack of training in nutrition, and inadequate instructional materials were revealed as factors capable of limiting teachers' operational teaching practices. If the benefits of school NE are to be fully realized, it is imperative that adequate modifications be put in place to improve the three areas revealed in this study. First, it is necessary to secure adequate time for teaching nutrition in the classroom to change the eating behaviors of learners positively. If it takes 50 hours per year to impart attitudes and behaviors (Briggs, Fleschhacker, and Mueller 2010), the realization of healthy eating behavior within the few hours of teaching nutrition as revealed in this study may be challenging. Second, teachers need to be trained in nutrition and to update their nutrition knowledge and understanding through in-service training. Our findings suggested that NE intervention (nutrition training) for these teachers could be irrespective of gender and/or teachers' level of education. Third, there should be adequate provision of quality reference and instructional materials at the schools in line with nutrition topics in the DoBE curriculum.

The teaching of nutrition both as a subject and as integrated into other subjects as recommended by FAO (2005) has the capacity of producing a synergy between the benefits of NE and the strengthening of its influence both in the short and long term.

\section{Acknowledgments}

The authors acknowledge the roles of the Department of Basic Education (DoBE) in granting permission to conduct the study, the principals and the teachers of the 11 schools for participating in the study, and Professor Piet Becker, PhD, of the Faculty of Health Sciences, University of Pretoria, for statistical analysis of data. 


\section{Funding}

This study was funded by the University of Pretoria's Strategic Institutional Research Theme through the Institute for Food, Nutrition and Wellbeing (IFNuW), the Nestle Nutrition Institute Africa (NNIA), and the Association of African Universities (AAU).

\section{References}

Briggs, M., S. Fleschhacker, and C. G. Mueller. 2010. Position of the American Dietetic Association, School Nutrition Association, and Society for Nutrition Education: Comprehensive school nutrition services. Journal of Nutrition Education and Behaviour 42 (6):360-71. doi:10.1016/j.jneb.2010.08.007.

California School Food Service Association (CSFSA). 2003. Position statement: Nutrition education. http://www.calsna.org/documents/PositionPapers/NutritionEducation (accessed March 26, 2015).

Celebuski, C., and E. Farris. 2000. Nutrition education in public elementary school class- rooms, K - 5. FRSS. National Center for Education Statistics. US Department of Education. https://catalyst.library.jhu.edu/catalog/citation (accessed July 8, 2012).

Culinary Institute of America. 2012. A national initiative to improve the health of $\mathrm{K}-12$ students through food education, culinary strategy and flavour insight. http://www.ciapro chef.com/healthykids (accessed November 26, 2012).

Dalais, L., Z. Abrahams, N. P. Steyn, A. de Villiers, J. M. Fourie, J. Hill, E. V. Lambert, and C.E. Draper. 2014. The association between nutrition and physical activity knowledge and weight status of primary school educators. South African Journal of Education 34 (3):817-24. doi:10.15700/201409161057.

Department of Basic Education (DoBE). 2011a. National curriculum statement (NCS). Curriculum and assessment policy statement (CAPS) grades $4-6$ : Natural Sciences and Technology. http://www.edu.gov.za (accessed March 25, 2015).

Department of Basic Education (DoBE). 2011b. National curriculum statement (NCS). Curriculum and assessment policy statement (CAPS) grades 4 - 6: Life Skills. http:// www.edu.gov.za (accessed March 25, 2015).

Department of Basic Education (DoBE). 2015. National School Nutrition Programme. http:// www.education.gov.za/Programmes/NationalSchoolNutrition (accessed May 5, 2015).

Department of Health South Africa (DOH). 2008. National Food Consumption Survey - Fortification Baseline (NFCS-FB-1) South Africa. 2005. Executive summary. South African Journal of Clinical Nutrition 21 ((3) (Suppl. 2)):255-66.

Faber, M., S. Laurie, M. Maduna, T. Magudulela., and E. Muehlhoff. 2013. Is the school food environment conducive to healthy eating in poorly resourced South African schools? Public Health Nutrition 7 (6):1214-23.

FAO. 2005. Nutrition education in primary schools. Vol. 1. The Reader. Rome: FAO. http:// www.fao.org/3/aa0333e.pdfaccessed March 18, 2015).

Ghasemi, A., and S. Zahediasl. 2012. Normality tests for statistical analysis: A guide for non-statisticians. International Journal of Endocrinology and Metabolism 10 (2):486-89. doi:10.5812/ijem.

Hill, J., C. E. Draper, A. De Villiers, J. M. Fourie, S. Mohamed, W. Parker., and N. Steyn. 2015. Promoting healthy lifestyle behaviour through the Life-Orientation curriculum: Teachers' perceptions of the HealthKick intervention. South African Journal of Education 35 (1):981-89. doi:10.15700/201503070003. 
KPMG International. 2008. Evaluation of the school nutrition programme: National report. UNICEF - South Africa Department of Education, Pretoria, South Africa.

Kupolati, M. D., G. J. Gericke., and U. E. MacIntyre. 2015. Teachers' perceptions of school nutrition education's influence on eating behaviours of learners in the Bronkhorstspruit District. South African Journal of Education 35 (2):1-10. doi:10.15700/201409161038.

Lambert, L. G., and D. H. Carr. 2006. Perceptions of elementary school nutrition education practices by school foodservice directors, teachers, and principals. Journal of Child Nutrition and Management. http://docs.schoolnutrition.org/newsroom/jenm/06spring/lambert/index accessed March 21, 2015).

McNulty, J. 2013. Challenges and issues in nutrition education. Rome: Nutrition Education and Consumer Awareness Group, Food and Agriculture Organization of the United Nations http://www.fao.org/ag/humannutrition/nutritioneducation/en (accessed March 12, 2015).

Nguyen, K. A., A. De Villiers, J. M. Fourie, L. T. Bourne., and M. K. Hendricks. 2013. The feasibility of implementing food-based dietary guidelines in the South African primary- school curriculum. Public Health Nutrition 9: 1475-2727. doi:http://dx.doi:10.1017/ S1368980013003194 (accessed December 10, 2014).

Oldewage-Theron, W., and A. Egal. 2012. Impact of nutrition education on nutrition knowl- edge of public school educators in South Africa: A pilot study. Health SA Gesondheid 17 (1). http://dx.doi.org/10.4102/hsag.v17i1.602 (accessed December 2, 2012).

Procter, S. B., and C. G. Campbell. 2014. Position of the Academy of Nutrition and Dietetics: Nutrition and lifestyle for a healthy pregnancy outcome. Position Paper. Academy of Nutrition and Dietetics 114 (7):1099103. doi:10.1016/j.jand.2014.05.005.

Rafiroiu, A. C., and A. Evans. 2005. Nutrition knowledge, attitudes and practices among nutrition educators in the South. American Journal of Health Studies 20:29-38.

Rossiter, M., T. Glanville, J. Taylor., and I. Blum. 2007. School food practices of prospective teachers. Journal of School Health 77 (10):694-700. doi:10.1111/j.1746-1561.2007.00253.x.

Statistics South Africa. 2010. Millennium development goal 2 - Achieve universal primary education. http://statssa.gov.za/MDG/2010_MDG_GOAL_2 (accessed September 7, 2015).

U.S. Department of Education, National Center for Education Statistics. 2015. Enrolment trends by age. http://nces.ed.gov/programs/coe/indicator_cea.asp (accessed September 7, 2015).

UNICEF. 2009. Tracking progress of child and maternal nutrition - a survival and development priority. New York, NY: UNICEF.

VanVoorhis, W. C. R., and B. L. Morgan. 2007. Understanding power and rules of thumb for determining sample sizes. Tutorials in Quantitative Methods for Psychology 3 (2):43-50.

WHO. 2006. Nutrition friendly school initiatives. A school-based programme to address the double burden of malnutrition. http://www.who.int/nutrition/topics/NFSI_Briefing (accessed March 26, 2015). 